\title{
Misconceptions of Upper-Secondary School Students on Doing Behavioral Sciences Research
}

Yousra Piro ${ }^{1}$, Britt Wevers ${ }^{1}$, Louise Maddens ${ }^{1,2}$, Annelies Raes ${ }^{1,2,3}$, Jan Elen $^{1}$

1) KU Leuven, Centre for Instructional Psychology and Technology

2) ITEC, imec research group at KU Leuven, Imec, Leuven, Belgium

3) CIREL - Centre Interuniversitaire de Recherche en Education de Lille (ULR 4354), Villeneuve- d'Ascq, France

Date of publication: February $24^{\text {th }}, 2022$

Edition period: February 2022 - June 2022

To cite this article: Piro, Y., et al. (2022). Misconceptions of UpperSecondary School Students on Doing Behavioral Sciences Research. International Journal of Educational Psychology, 11(1), 29-49. doi: 10.17583/ijep.9296

To link this article: http://dx.doi.org/10.17583/ijep.9296

PLEASE SCROLL DOWN FOR ARTICLE

The terms and conditions of use are related to the Open Journal System and to Creative Commons Attribution License (CC-BY). 


\section{Misconceptions of Upper- Secondary School Students on Doing Behavioral Sciences Research}

Yousra Piro, Britt Wevers, Louise Maddens, Annelies Raes, Jan Elen

KU Leuven, Centre for Instructional Psychology and Technology, Belgium ITEC, imec research group at KU Leuven, Imec, Leuven, Belgium CIREL-Centre Interuniversitaire de Recherche en Education de Lille, France

\begin{abstract}
With its long tradition, research on misconceptions helps to understand how concepts are learned and how learning in the disciplines can be supported. Up to now, research on misconceptions has focused on natural sciences, while research on misconceptions in behavioral sciences is scarce, not to say absent. In this study an attempt was made to reveal upper secondary school students' misconceptions on doing research in behavioral sciences. The starting point for the study were research proposals of upper secondary school students. As part of a larger study, students were asked to write a research proposal in maximum two pages. A twosteps approach was adopted in the analysis of these research proposals. First, using a codebook containing both deductive and inductive codes, two-pagers were analyzed in order to identify 'errors'. In a second step, an interpretative analysis aimed at inferring potential misconceptions underlying these errors. The study can be considered as a starting point for research on misconceptions in behavioral sciences which is currently missing in the field.
\end{abstract}

Keywords: Misconceptions; Conducting research; Behavioral sciences; Explorative study.

2022 Hipatia Press

ISSN: 2014-3567

DOI: $10.17583 /$ ijep.9296 www.hipatiapress.com

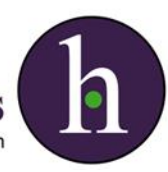

Hipatia Press 
No. 1 February 2022 pp. 29-49

\section{Conceptos Erróneos de los Estudiantes de Secundaria sobre la Investigación en Ciencias del Comportamiento}

Yousra Piro, Britt Wevers, Louise Maddens, Annelies Raes, Jan Elen

KU Leuven, Centre for Instructional Psychology and Technology, Belgium ITEC, imec research group at KU Leuven, Imec, Leuven, Belgium

CIREL-Centre Interuniversitaire de Recherche en Education de Lille, France

\section{Resumen}

Con su larga tradición, la investigación sobre los conceptos erróneos ayuda a comprender cómo se aprenden los conceptos y cómo se puede apoyar el aprendizaje en las disciplinas. Hasta ahora, la investigación sobre los conceptos erróneos se ha centrado en las ciencias naturales, mientras que la investigación sobre los conceptos erróneos en las ciencias del comportamiento es escasa, por no decir inexistente. En este estudio se intentó revelar los conceptos erróneos de los estudiantes de secundaria superior sobre la realización de investigaciones en ciencias del comportamiento. El punto de partida del estudio fueron las propuestas de investigación de los estudiantes de secundaria superior. Como parte de un estudio más amplio, se pidió a los estudiantes que redactaran una propuesta de investigación en un máximo de dos páginas. Para el análisis de estas propuestas de investigación se adoptó un enfoque en dos fases. En primer lugar, utilizando un libro de códigos que contenía códigos deductivos e inductivos, se analizaron las propuestas de dos páginas para identificar los "errores". En un segundo paso, se realizó un análisis interpretativo con el fin de inferir posibles conceptos erróneos subyacentes a estos errores. El estudio puede considerarse un punto de partida para la investigación sobre las concepciones erróneas en las ciencias del comportamiento, que actualmente no existe en este campo.

Palabras clave: Conceptos erróneos; Realización de investigaciones; Ciencias del comportamiento; Estudio exploratorio. 


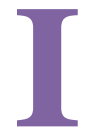

$\mathrm{n}$ the process of solving problems, people make errors. While some of these errors result from a lack of attention or from knowledge deficiencies, others are the result of misconceptions related to key aspects of the problems at hand. Therefore, it is not surprising that ample studies in different disciplines have focused on identifying misconceptions, better understanding (the origins and evolutions of) misconceptions, and on teaching conceptions while handling misconceptions and/or preventing their development.

Most of the research on misconceptions has been conducted in natural sciences disciplines, emblematic is the research of Vosniadou (1994) on astronomy among primary school kids. Given the sheer absence of research on misconceptions in behavioral sciences on the one hand and the importance of 'doing research' in Flemish behavioral sciences curricula ${ }^{1}$ on the other hand, this project aimed at identifying misconceptions of upper secondary school students on doing research in behavioral sciences. We define behavioral sciences as the study of human behavior (in psychology, educational sciences, cultural and social sciences).

As a conceptional starting point, first, an overview is given of research on misconceptions in general and on misconceptions about doing research in particular. The adopted two-steps approach is presented in the methods section, followed by a description of the outcomes in the results section. Next, the results are discussed in view of the current literature. In the concluding section, limitations of the work and implications for future research are discussed.

\section{Conceptual Background}

\section{Misconceptions}

While a generally accepted definition of misconceptions is missing (Leonard, Kalinowski, \& Andrews, 2014), misconceptions are generally conceived as ideas or convictions that deviate from scientifically accepted explanations (e.g., Vosniadou, 2019). There is no general agreement on the nature of misconceptions nor on how to react to them. A view in which 
misconceptions are conceived as stable, difficult to alter cognitive structures (Hammer, 1996; Schmidt et al., 1988) contrasts, for instance, with a view of misconceptions as cognitive components that are loosely coupled and continuously evolving. In the latter case misconceptions can evolve in more grounded conceptions although they may also remain unchanged in case they appear sufficiently functional in multiple domains / situations (Schmidt et al., 1988).

While views on the exact nature, the functionality and the stability of misconceptions differ, there seems to be some consensus that a misconception is not to be confused with a lack of knowledge. Similarly, there seems to be some consensus that errors and misconceptions are different things. Errors can be due to lack of attention, lack of knowledge and/or can be the observable result of underlying misconceptions. Without arguing in favor of a one-to-one relationship between errors and misconceptions, it is generally accepted that misconceptions may result in a pattern of errors and vice versa.

\section{Conducting Research}

This study focuses on conducting research in behavioral sciences. Rather than looking for research attitudes which pertain to how an individual relates to (different) aspects of doing research, the focus is on research activities: the activities performed in a research process.

In this study the descriptive framework of Fischer et al. (2014) will be used as it is comprehensive, operational and the result of an in-depth literature review. It is also generative as it has been used as the framework for ample research in the past years (e.g., Maddens et al., 2019). Fischer et al. (2014) distinguish eight (groups of) research activities, i.e.: (1) problem identification, (2) questioning, (3) hypothesis generation, (4) construction and redesign of artefacts, (5) evidence generation, (6) evidence evaluation, (7) drawing conclusions and (8) communicating and scrutinizing.

\section{Misconceptions on Conducting Research}

Research on misconceptions in different disciplines revealed that misconceptions in a discipline may strongly affect further learning in that discipline. As misconceptions affect disciplinary reasoning, the same pertains to problem solving in that discipline. 
With respect to research activities, a meta-analysis by Earley (2014) shows that freshmen do hold misconceptions about doing research. Students developed these misconceptions during secondary education and these misconceptions seem to negatively affect learning about research methodology. Woolley et al. (2018) similarly demonstrated the negative impact of misconceptions on doing research.

As was mentioned, most studies on misconceptions have been performed in natural sciences domains (see for example Schmidt et al., 1988; Kumandas et al., 2019). Meyer and colleagues $(2005,2007)$ investigated conceptions about research among higher education students from a variety of discipline backgrounds. In the open-ended written responses of students to questions related to conceptions towards research, they identified different dimensions, one of which immediately relates to misconceptions. The following misconceptions were retrieved:

- Good research implies collecting data that confirm the arguments or ideas of the researchers.

- Well-executed research procedures will always result in positive results.

- Research done by qualified persons will never bring about biased results.

- It is acceptable to alter research data that are inadequate.

- Research becomes true as soon as it gets published.

- Well executed studies will never result in contrasting research findings.

- In general, there is only one right way to interpret research findings.

Most studies on doing research have been investigating the research activities of students in higher education. Research with students in secondary schools is very limited. Moreover, research has focused on natural sciences. Illustrative is the review of de Jong and van Joolingen (1998) who thoroughly identified the problems students encountered in doing research based on the errors they made while engaging in research activities.

\section{Research Questions}

Given the current state of the art with a dominance of research on errors in natural sciences and among higher education students, this study aims to explore the misconceptions of upper secondary school students on doing 
research in behavioral sciences. The current study makes a clear distinction between errors and misconceptions. Whereas errors can be observed when looking at research activities students engage in or based on what students tell about research, misconceptions need to be inferred as they pertain to the conceptions and reasonings that result in the errors. Furthermore, it is important to stress that a one-on-one relationship between errors and misconceptions is not assumed.

\section{Methods}

The study adopts a qualitative research approach in two steps of analysis: identification of errors and inference of misconceptions. It is part of a larger effort to stimulate the development of research skills among students in upper secondary education who study 'behavioral sciences' (see Maddens, Depaepe, Raes, \& Elen, 2020) which was approved by the Social and Societal Ethics Committee of the university. As part of an intervention study, all involved students were requested to write and submit a research proposal of maximum two pages (hence 'two-pager') starting from the assignment with three instructions: (1) describe a research question and its significance, (2) clarify how the question will be answered (data gathering methodology and target group), and (3) explain the expected research outcomes and how these will be reported. In total 147 two-pagers were elaborated. All of them are part of this study.

\section{Identification of Errors}

Errors were identified through a systematic descriptive document analysis using a gradually developed codebook. The codebook is the result of a deductive and an inductive process. Based on an exploration of the literature (described above) and using Fischer's framework (2014) as a starting point, an initial set of 26 potential errors were identified. Two errors were transversal (i.e., 'unsystematic research with only ad hoc decisions', and 'confounding correlation and causality'), whereas all other errors were linked to a specific activity in Fischer's framework (e.g., generating evidence: looking for evidence that supports the hypothesis).

Considering that deductive codes might not be sufficiently powerful to grasp the data from within (Billiet \& Waege, 2010), inductive codes were 
elaborated as well. Initially, 20 two-pagers were randomly selected to be used during the elaboration of the codebook. They were analysed in groups of five. After a systematic description of all 20 two-pagers in order to allow for comparisons, all of them were carefully and repeatedly scrutinized in order to identify potential errors. Using NVivo10, the different potential errors were annotated. First, annotations were added to fragments with potential errors. More specifically, these annotations shortly (in one or two sentences) described what could be considered problematic in the fragment. Second, after a thorough investigation of these descriptions in the 20 two-pagers, error codes were defined. Again, two-pagers were looked at in groups of five. In case at least three new error codes emerged while analyzing a group of five two-pagers, the analyzing process continued with another group of five twopagers, until a saturation point was reached. After having analyzed another 25 two-pagers (on top of the 20 initial two-pagers), this criterium was met.

Hence, the final codebook is based on the initial deductive set and the inductive set elaborated based on 45 two-pagers and contains 40 error codes. Prior to a systematic use of the codebook, an interrater reliability check was done. Two researchers independently coded 10 two-pagers. They reached an agreement of $96.53 \%$ which is regarded to be high (Volpe et al., 2009).

Using the codebook, each of the two-pagers was systematically analysed and coded by one of the two researchers, each of them processed half of the two-pagers. This entailed an analysis of each of the two-pagers as to enable a systematic comparison of the two-pagers, annotating the description in NVivo 10 , and coding the annotations.

\section{Identification of Misconceptions}

As was specified, misconceptions of interest in this study are conceived as ideas or reasonings that may results in errors with respect to conducting research in behavioral sciences. Hence, misconceptions are induced from errors. A significant part of the analysis thus consisted of studying what misconceptions could underlie the errors identified in the two-pagers. A oneto-one relationship was not presumed. In other words, a misconception may result in different errors and at the same time, an error might be the result of a combination of misconceptions. 
Using an iterative process, the (manifestations of the) errors were inspected. The main question asked was what misconception might result in that particular error. More specifically, attention was paid to possible similarities and differences in the different manifestations of the errors. Similarities in the manifestations of errors might refer to a common misconception, while differences may point to different underlying misconceptions. Given the fact that no one-to-one relationship can be observed between errors and misconceptions, a two-step (error-based and misconception-based) approach was iteratively adopted. First, misconceptions were induced from the errors. For all utterances referring to a specific error different potential misconceptions were identified. A final selection was made by carefully comparing similarities and differences among the utterances. The second step started from the misconceptions. For each misconception it was investigated what errors could be consistently attributed to the misconception. The twostep process was repeated until coherence and consistency were established.

Given that errors do not always result from a misconception, other potential sources of errors (e.g., lack of attention, lack of knowledge) were also considered. In other words, not for all errors it was possible to induce a misconception. In those cases, it was assumed that the errors resulted from other sources such a lack of attention or limited prior knowledge.

The outcome of the analysis is a set of potential misconceptions that may result in errors among upper secondary school students when it comes to conducting research.

\section{Results}

\section{Errors}

For 6 out of 40 error codes in the codebook no concrete instances could be retrieved. All of these codes are from the deductive set. Some of these errors (e.g., confirm hypotheses despite evidence) could not be retrieved as the twopagers do not contain specific research findings (students were asked to write a research proposal, and as such, the study described in the two-pagers was not conducted). In total, 696 errors were retrieved in the 147 two-pagers. It is important to stress that the goal of this study is not to retrieve what aspects of doing research are more or less difficult for students. Rather, the errors are identified to establish possible underlying misconceptions. Notwithstanding, 
the study gives some initial and explorative indications related to the frequency of the errors that deserve further verification. In table 1, an overview is given of errors categorized along the classification framework of Fischer et al. (2014) with the addition of a transversal category.

\section{Table 1}

Errors in two-pagers

\begin{tabular}{|c|c|c|c|c|}
\hline Error Category & Enror & $\begin{array}{l}\text { Number } \\
\text { enrors }\end{array}$ & $\begin{array}{l}\text { Number errors } \\
\text { in category }\end{array}$ & $\begin{array}{c}\text { Total number } \\
\text { of errors }\end{array}$ \\
\hline Problem & No scientific support for & 44 & 44 & 696 \\
\hline identification & 'scientific problem' & & & \\
\hline \multirow[t]{2}{*}{ Questioning } & No specification of target & 17 & 17 & \\
\hline & group & & & \\
\hline \multirow{9}{*}{$\begin{array}{l}\text { Hypothesis } \\
\text { generation }\end{array}$} & Broad hypothesis that cannot & 1 & 95 & \\
\hline & be falsified & & & \\
\hline & Confusion between hypothesis & 0 & & \\
\hline & and prediction & & & \\
\hline & No scientific support for & 51 & & \\
\hline & hypothesis & & & \\
\hline & No link between research & 36 & & \\
\hline & question and hypothesis & & & \\
\hline & Contradictory hypotheses & 7 & & \\
\hline \multirow{11}{*}{$\begin{array}{l}\text { Construction } \\
\text { and redesign of } \\
\text { artefacts }\end{array}$} & Insufficient operationalization & 30 & 223 & \\
\hline & of relevant variables & & & \\
\hline & Tailor experiment towards & 2 & & \\
\hline & results aimed at & & & \\
\hline & $\begin{array}{c}\text { Fun, creative experiment rather } \\
\text { than functional one }\end{array}$ & 1 & & \\
\hline & Absence of link between & 53 & & \\
\hline & $\begin{array}{c}\text { methodology and research } \\
\text { question }\end{array}$ & & & \\
\hline & $\begin{array}{c}\text { No operational definition of } \\
\text { target group }\end{array}$ & 50 & & \\
\hline & $\begin{array}{l}\text { Unclear specification of } \\
\text { research methods }\end{array}$ & 29 & & \\
\hline & Unrealistically large samples & 17 & & \\
\hline & $\begin{array}{c}\text { Problematic elaboration of } \\
\text { research method }\end{array}$ & 15 & & \\
\hline
\end{tabular}


Selecting unrealistic research

methods

Neglecting differences among

variables

Mismatch between target group

and sample

Confusion between investigated

relationship and investigated

variable

Consider variable representing

other variables

\begin{tabular}{|c|c|c|c|}
\hline \multirow[t]{5}{*}{$\begin{array}{l}\text { Evidence } \\
\text { generation }\end{array}$} & $\begin{array}{c}\text { Investigating variables that are } \\
\text { not in the research question }\end{array}$ & 23 & 33 \\
\hline & $\begin{array}{l}\text { Looking for confirming } \\
\text { evidence }\end{array}$ & 3 & \\
\hline & $\begin{array}{l}\text { Investigating multiple variables } \\
\text { at the same time }\end{array}$ & 3 & \\
\hline & $\begin{array}{c}\text { Manipulating variables at free } \\
\text { will and unsystematic }\end{array}$ & 1 & \\
\hline & $\begin{array}{c}\text { Neglect important } \\
\text { characteristics of variables, } \\
\text { although documented in } \\
\text { research }\end{array}$ & 3 & \\
\hline \multirow[t]{5}{*}{$\begin{array}{l}\text { Drawing } \\
\text { conclusions }\end{array}$} & $\begin{array}{c}\text { Confirm hypotheses despite } \\
\text { evidence }\end{array}$ & 0 & 16 \\
\hline & $\begin{array}{l}\text { Purely local interpretation of } \\
\text { evidence }\end{array}$ & 0 & \\
\hline & $\begin{array}{c}\text { Confute hypotheses despite } \\
\text { evidence }\end{array}$ & 0 & \\
\hline & $\begin{array}{c}\text { No check of reliability of the } \\
\text { collected evidence }\end{array}$ & 0 & \\
\hline & $\begin{array}{l}\text { Formulating evidence while } \\
\text { collecting insufficient evidence }\end{array}$ & 0 & \\
\hline
\end{tabular}




\begin{tabular}{|c|c|c|c|}
\hline & $\begin{array}{l}\text { No specific plan to link data } \\
\text { with research questions }\end{array}$ & 16 & \\
\hline Evidence & No generalization of findings & 6 & 18 \\
\hline evaluation & $\begin{array}{l}\text { Mismatch between aimed at } \\
\text { conclusions and evidence }\end{array}$ & 12 & \\
\hline $\begin{array}{l}\text { Communicating } \\
\text { and scrutinizing }\end{array}$ & $\begin{array}{l}\text { Report cannot adequately } \\
\text { represent evidence generated }\end{array}$ & 10 & 10 \\
\hline \multirow[t]{6}{*}{ Transversal } & $\begin{array}{c}\text { Confusion among correlation } \\
\text { and causality }\end{array}$ & 56 & 240 \\
\hline & $\begin{array}{c}\text { Lack of planning with mostly } \\
\text { ad hoc decisions that cannot be } \\
\text { monitored }\end{array}$ & 1 & \\
\hline & $\begin{array}{l}\text { Research design deviates from } \\
\text { research question }\end{array}$ & 64 & \\
\hline & $\begin{array}{c}\text { Neglecting practicalities of } \\
\text { doing research }\end{array}$ & 52 & \\
\hline & $\begin{array}{l}\text { Positive bias towards the } \\
\text { research question }\end{array}$ & 48 & \\
\hline & $\begin{array}{c}\text { Mixing characteristics of } \\
\text { quantitative and qualitative } \\
\text { research }\end{array}$ & 19 & \\
\hline
\end{tabular}

Note. Deductive codes are in italic

From each category the most prominent one is briefly presented as to illustrate the errors. With respect to problem identification, students regularly propose a research problem they argue to be relevant for research. Rather than referring to scientific relevance, topics are selected based on personal experiences or personal interest.

"Personally, I think this question is very interesting (...) I am a member of a youth movement myself" (Two-pager 101).

When it comes to specifying a research question, in ample two-pagers the target group is not specified or in very general terms only (e.g., 'everybody (two-pager 5) or 'mankind in general' (two-pager 134)). 
Generating hypotheses rooted in science seems difficult. In the two-pagers general hypotheses are put forward without any argumentation, underscored by referring to 'personal expectations' (e.g. two-pager 70) or by general statements such as 'very stereotype' (two-pager 32).

A recurring error with respect to research methodology is the absence of a link between the proposed methodology and the research question. There are different variations in this error. Some students want to use survey instruments to retrieve the causal relationships between variables (e.g., time invested in studying and exam results) (two-pagers 101 and 115). Some other students aim at studying the quantity of variables (e.g., 'what in general is motivating students the most' using qualitative interviews (two-pager 90).

While collecting data, students sometimes plan to collect data that have no link with a research question. For instance, it is proposed to investigate what the best possible activities are to relax during a cram period with 'concentration as one of the dependent variables' (two-pager 81). In another study it is investigated why depression among pupils is that high while questions in the research instrument pertain to 'how the persons would like to be supported' (two-pager 118).

While in the two-pagers limited information is available on actual evidence, in some cases it becomes clear that there is not a specific plan on how to use the collected data in view of answering the research question. For instance, a research is proposed to investigate the impact of the use of Netflix on study outcomes (two-pager 50) and information will be gathered on 'Netflix information (number of hours, when, what series), school results (observation), results of the experiment, questionnaires and a short interview'. In the two-pager it is put forward that 'from the collected data a possible relationship will follow'.

In the instruction for the two-pagers expected outcomes are requested. The expected outcomes however often do not match the methodology. For example, in a two-pager, a student wants to investigate the extent to which students with a migration background are confronted with discrimination by means of a questionnaire and hopes to draw conclusions 'on the extent to which discriminating behavior increases or decreases over the years' (twopager 112).

A mismatch is also retrieved in a number of cases between expected conclusions and evidence to be gathered. In one proposed study for instance, 
it is proposed to investigate the relationship between climate change on the one hand and the reduction of biodiversity on the other hand. However, one aims at concluding that 'there are still solutions that can be applied on the short term' while solutions are not part of the research (two-pager 142).

In a number of cases, ways of reporting are scheduled that do not match the possible research outcomes. In some two-pagers it is proposed to simply present the outcomes visually without further clarification. For instance, the following is mentioned "I could write it down in an elaborate report, but I think it will be better to present it in one graphic or scheme" (two-pager 30).

One of the often-recurring transversal errors pertains to a mismatch between the research question and the proposed methodology. When specifying the research methods, the focus of several two-pagers deviates from the research questions. For instance, it is proposed 'to investigate why so little is spoken about (mental) problems and why they are taboo'. The proposed method is a questionnaire about well-being of pupils in different study-tracks (two-pager 4).

\section{Misconceptions}

The major aim of this study is to induce a set of misconceptions possibly underlying the errors retrieved in the two-pagers. Inference requires analysis and interpretation starting from the question 'What misconception may result in this error?'.

As errors might have different causes, it is not surprising that not for all errors a potential underlying misconception was identified. It is assumed that a lack of knowledge or insufficient attention resulted in the following errors.

- Insufficient operationalization of relevant variables

- Fun, creative experiment rather than functional one

- No operational definition of target group

- Neglecting differences among variables

- Unclear specification of research methods

- Consider variable representing other variables

- Confusion between investigated relationship and investigated variable

- Mixing characteristics of quantitative and qualitative research

- Neglecting practicalities of doing research 
Further inspection of the misconceptions reveals that at least two levels of misconceptions can be identified. Of all 23 misconceptions, 4 represent more overarching misconceptions (first level misconceptions).

A first overarching misconception is that what is personally relevant is also scientifically relevant. There are two instantiations. Firstly, it is conceived that any personal opinion has scientific relevance, and second, that what is personally interesting is also scientifically relevant. These misconceptions may result in errors with respect to selecting scientifically relevant research problems and with respect to the lack of scientific argumentation of hypotheses.

A second, related but different overarching misconception is that for doing research, taking into account what is known about the topic under study in the existing literature is not required. The misconception downsizes the importance of embedding new research in the research tradition. The instantiations are identical to the previous overarching misconception. It results in errors with respect to scientifically underpinning research problems and hypotheses.

A third overarching misconception relates to research quality. It is the idea that the extent/ the magnitude of research is an indicator of research quality (more is better). There are different instantiations.

- Quality of research is dependent on the reach of the target group. In other words the quality of research is dependent on the number of people that may be addressed by the research problem. It results in not specifying the target group.

- Quality of research is dependent on the size of the sample. This misconception may result in proposing unrealistically large samples.

- Quality of research is dependent on the complexity of the research methods. The idea is that good research is characterized by complex designs and/or a lot of different research instruments. It may result in errors with respect to unrealistic and dysfunctional research approaches.

- Quality of research is dependent on the number of variables. The more variables, it is assumed, the better the research. This results in errors such as including variables that were not specified in the research questions and/or the manipulation of multiple variables at the same time. 
- Quality of research is dependent on the reach of the conclusion. The ambition seems to be to formulate the conclusions as broad as possible. A consequential error might be that the conclusions are not fully in line with the evidence, a case of over-generalisation.

- Any type of report can adequately present research findings disregard the research question and/or the nature of the research. The misconception results in underspecifying the type of report or to select an inappropriate type given the nature of the research.

A fourth overarching misconception is that different components of a research (process) can be considered separately. Overall, this misconception may result in mismatches between different components of a research (process) as indicated by more specific misconceptions:

- Research questions and hypotheses can be formulated independently. This results in possible mismatches between research questions and hypotheses.

- Research questions and research methods can be elaborated independently. The resulting error might be that research methods are selected by means of which it is impossible to answer the research question.

- Research questions and conclusions can be formulated independently. Consecutive errors may pertain to broadly formulated conclusions that do no longer match the initial research question although they still may pertain to the general research problem.

- Research questions and reporting methods can be decided upon independently. An error resulting from this misconception might be that a report is elaborated that cannot provide a comprehensible answer to the research question.

- Research questions and research methods can be decided upon independently. As a consequence, methods might be selected that are not functional as to answering the research question.

- Target group and sample can be selected independently. The assumption seems to be that a sample does not necessarily is a subset of the target group. The problem will be that generalizing towards the target becomes impossible. 
- Throughout a research process ad hoc decisions can be taken. This misconception results in a lack of systematicity, variables are manipulated and changed during the process and efforts to monitor continuity are missing.

The remainder of the misconceptions seem to be more specific although their impact on making errors might be vast. The following specific misconceptions were identified:

- Research is oriented towards verification. This misconception may result in very different errors such as (a) formulating very broad hypotheses that can hardly be falsified, (b) elaborating an experiment that can only generate the expected results, (c) looking for evidence that will support the intended outcomes, (d) specific bias towards the research question, but also (e ) proposing contradictory hypotheses in order to ensure that at least one of them will get supportive evidence.

- Cohesion is a robust indicator of causality. This is of course closely related to the misconception about the relationship between correlation and causality. It results in errors with respect to selecting appropriate research methods but also with respect to interpreting specific findings.

- Any research question can be investigated with any research method. The consequence is a potential mismatch between research question and research method and the impossibility to get a reasonable answer.

- One characteristic of a variable can adequately represent that variable. Such a misconception results in inadequate assessment of some variables. When for instance a distinction is made between two aspects of a variable, it is assumed that assessing one aspects is sufficient as to make statements about the other aspect.

- Raw data are self-explanatory. The misconception results in the idea that no analysis of data is needed and hence that multiple interpretations are not possible. It results in an under-specification of data analyses.

- Sampling is impossible. This misconception argues that a statement about a target group can be made only when all members of the target group are involved in the study. The misconception largely neglects the entire discipline of inferential statistics. 


\section{Discussion and Conclusion}

This explorative study aimed at identifying misconceptions about conducting research in behavioral sciences among upper secondary school students which was currently lacking in the field. Overall, 23 potential misconceptions are proposed, most of which can be categorized under four more overarching misconceptions (i.e., 'what is personally relevant is also scientifically relevant'; 'taking into account what is known about the topic under study in the existing literature is not required'; 'the extent/ the magnitude of research is an indicator of research quality', and 'different components of a research (process) can be considered separately').

To some extent the findings align with previous research of Meyer et al. $(2005,2007)$. This is for instance the case for the misconception that research is oriented towards verification. This misconception may result in various errors with respect to hypotheses, research methodology as well as interpretation and reporting. Another example relates to the misconception that what is personally relevant is also scientifically relevant. In terms of Meyer et al. $(2005,2007)$ this may result in looking for evidence that supports the researcher's ideas or arguments. Finally, the misconception that raw data are self-explanatory can be related to the misconception as proposed by Meyer et al. (2007) that "There is generally only one way to interpret research findings" (p. 233).

This study reveals that misconceptions are related to one another in different ways. They may pertain in different ways to different components of conducting research and are layered. It is possible to identify specific, but also overarching misconceptions. At least, this supports the idea that misconceptions are part of a knowledge network as has already been proposed by Smith et al. (1993). This may be the starting point of efforts to handle misconceptions in classrooms in line with the theory-based recommendations in the field of natural sciences (e.g., Vosniadou, 2020).

The study also presents a new methodology to unravel misconceptions. Rather than directly identifying misconceptions as was done by Meyer et al. (2005) or by restricting oneself to identifying errors in doing research, this study adopted a two-step process by first identifying errors and then inducing possible misconceptions based on these errors. With respect to the identification of the errors an iterative approach was adopted using both 
deductive and inductive codes. Due to the nature of the two-pager task, in which students reflected on their research plans, while they did not actually need to perform the study, some of the errors related to deductive codes could not be retrieved. However, the codebook can be applied in future research in the field of behavioral sciences to research tasks involving an entire research process (including data collection and data analysis). As such, it is important to stress that the non-occurrence of specific codes in this study does not imply that students might not make errors (or hold misconceptions) towards these aspects of doing research.

Next to the added value of this work, it has to be noted that the study is explorative and has some limitations. A first limitation relates to the use of two-pagers that were elaborated in the context of a broader intervention study. Although a rather large set of two-pagers was used, the sample was not random but specific for those who participated in the broader study. Moreover, participants received particular instructions to elaborate the research proposal and those instructions had an impact on the two-pagers that were actually submitted. Moreover, as was mentioned, the two-pagers are research proposals, and therefore, they do not report on actual research activities. As such, important aspects of doing research, such as data gathering and data analyses, are missing in the two-pagers.

Furthermore, while the errors were systematically identified and high interrater reliability scores can be reported, the inference of the misconceptions has been at this point mostly a qualitative endeavor during which inferences were made. The list is therefore not presented as an exhaustive or final list but as a first proposal that requires further corroboration. The list might be the starting point of conceptual discussions (are they are well described, well grouped) on the one hand and of empirical work on the other hand. Firstly, empirical studies may investigate whether high school students actually hold these misconceptions. Secondly, one may study whether the list is useful in attempting to understand the errors students actually make. If the answer to the latter question is yes, then research might look for ways in which these misconceptions could be dealt with and perhaps even directly addressed during instruction. In this study no efforts were made to alter the misconceptions of the students. A first step in this respect could be to explicitly discuss these misconceptions with students (after validation in further research). Once a more robust list of misconceptions is available more 
quantitative research becomes possible about the prevalence of specific as well as of combinations of misconceptions.

As to conclude, this explorative study is regarded to be a first step in the direction of unveiling misconceptions high school students hold about conducting research in behavioral sciences. It may induce new research and help to expand the domain-specific research on misconceptions. It may therefore be seen as a very first step to adequately address these misconceptions.

\section{Notes}

${ }^{1}$ In Flanders, in upper secondary education, behavioral sciences is a specific full-time study track.

\section{References}

Billiet, J. \& Waege, H. (2010). Een samenleving onderzocht. In Methoden van sociaal-wetenschappelijk onderzoek. De Boeck.

de Jong, T., \& van Joolingen, W. R. (1998). Scientific discovery learning with computer simulations of conceptual domains. Review of Educational Research, 68(2), pp. 179-201. https://doi.org/10.2307/1170753

Earley, M. A. (2014). A synthesis of the literature on research methods education. Teaching in Higher Education, 19(3), pp. 242-253. https://doi.org/10.1080/13562517.2013.860105

Fischer, F., Kollar, I., Ufer, S., Sodian, B., Hussmann, H., Pekrun, R., Neuhaus, B., Dorner, B., Pankofer, S., Fischer, M., Strijbos, J. W., Heene, M., \& Eberle, J. (2014). Scientific reasoning and argumentation: Advancing an interdisciplinary research agenda in education. Frontline Learning Research, 2(3), pp. 28-45. https://doi.org/10.14786/flr.v2i2.96

Hammer, D. (1996). More than misconceptions: Multiple perspectives on student knowledge and reasoning, and an appropriate role for 
education research. American Journal of Physics, 64(10), pp. 13161325. http://dx.doi.org/10.1119/1.18376.

Kumandaş, B., Ateskan, A., \& Lane, J. (2019). Misconceptions in biology: a meta-synthesis study of research, 2000-2014. Journal of Biological Education, 53(4), pp.

350-364. https://doi.org/10.1080/00219266.2018.1490798

Leonard, M. J., Kalinowski, S. T., \& Andrews, T. C. (2014). Misconceptions yesterday, today and tomorrow. CBE Life Sciences Education, 13(2), 179-186. https://doi.org/10.1187/cbe.13-12-0244

Maddens, L., Depaepe, F., Janssen, R., Raes, A., \& Elen, J. (2019). Evaluating the Leuven Research Skills Test for 11th and 12th grade. Journal of Psychoeducational Assessment, 38(4), pp. 445-459. https://doi.org/10.1080/03055698.2020.1715204

Maddens, L., Depaepe, F., Raes, A., \& Elen, J. (2020). The Instructional Design of a 4C/ID-Inspired Learning Environment for Upper Secondary School Students' Research Skills. International Journal of Designs for Learning, 11 (3), 126-147. https://doi.org/10.1177/0734282918825040

Meyer, J. H. F., Shanahan, M. P., \& Laugksch, R. C. (2005). Students' conceptions of research. I: A qualitative and quantitative analysis. Scandinavian Journal of Educational Research, 49(3), pp. 225-244. https://doi.org/10.1080/00313830500109535

Meyer, J. H. F., Shanahan, M. P., \& Laugksch, R. C. (2007). Students' conceptions of research. II: An exploration of contrasting patterns of variation. Scandinavian Journal of Educational Research, 51(4), pp. 415-433. https://doi.org/10.1080/00313830500109535

Schmidt, H., Spaaij, G., \& de Grave, W. (1988). Opsporen van misconcepties bij middelbare scholieren. Tijdschrift voor Onderwijsresearch, 13(3), pp. 129-140. hdl.handle.net/1765/2728

Volpe, R.J., McConaughy, S.H., Hintze, J.M. (2009). Generalizability of classroom behavior problem and on-task scores from the Direct Observation Form. School Psychology Review, 38, pp. 382-401. https://doi.org/10.1080/02796015.2009.12087822

Vosniadou, S. (1994). Capturing and modeling the process of conceptual change. Learning and Instruction, 4(1), 45-69. https://doi.org/10.1016/0959-4752(94)90018-3 
Vosniadou, S. (2019). The development of students' understanding of science. Frontiers in Education, 4(32), pp. 1-6. https://doi.org/10.3389/feduc.2019.00032

Vosniadou, S. (2020).Students' Misconceptions and Science Education. Oxford Research Encyclopedia of Education. Retrieved 8 Feb. 2022 , from https://oxfordre.com/education/view/10.1093/acrefore/97801902640 93.001.0001/acrefore-9780190264093-e-965 .

Woolley, J. S., Deal, A. M., Green, J., Hathenbruck, F., Kurtz, S. A., Park, T. K. H., Pollock, S. V., Transtrum, M. B., \& Jensen, J. L. (2018). Undergraduate students demonstrate common false scientific reasoning strategies. Thinking Skills and Creativity, 27, pp. 101-113. https://doi.org/10.1016/j.tsc.2017.12.004

Yousra Piro: KU Leuven, Centre for Instructional Psychology and Technology

Britt Wevers: KU Leuven, Centre for Instructional Psychology and Technology

Louise Maddens: KU Leuven, Centre for Instructional Psychology and Technology; ITEC, imec research group at KU Leuven, Imec, Leuven, Belgium

Annelies Raes: KU Leuven, Centre for Instructional Psychology and Technology; ITEC, imec research group at KU Leuven, Imec, Leuven, Belgium; CIREL - Centre Interuniversitaire de Recherche en Education de Lille (ULR 4354), Villeneuve- d'Ascq, France

Jan Elen: KU Leuven, Centre for Instructional Psychology and Technology

Contact Address: jan.elen@kuleuven.be 